\title{
Transportation in Agent-Based Urban Modelling
}

\author{
Sarah Wise ${ }^{1}$, Andrew Crooks ${ }^{2}$, Michael Batty ${ }^{1}$ \\ ${ }^{1}$ Centre for Advanced Spatial Analysis, University College London, 90 Tottenham \\ Court Road, London W1T 4TJ, UK \\ s.wise@ucl.ac.uk \\ ${ }^{2}$ Department of Computational and Data Sciences, College of Science, George Mason \\ University, Research Hall, 4400 University Drive, MS 6B2, Fairfax, VA 22030, USA
}

\begin{abstract}
As the urban population rapidly increases to the point where most of us will be living in cities by the end of this century, the need to better understand urban areas grows ever more urgent. Urban simulation modelling as a field has developed in response to this need, utilising developing technologies to explore the complex interdependencies, feedbacks, and heterogeneities which characterise and drive processes that link the functions of urban areas to their form. As these models grow more nuanced and powerful, it is important to consider the role of transportation within them. Transportation joins, divides, and structures urban areas, providing a functional definition of the geometry and the economic costs that determine urban processes accordingly. However, it has proved challenging to factor transportation into agent-based models (ABM); past approaches to such modelling have struggled to incorporate information about accessibility, demographics, or time costs in a significant way. ABM have not yet embraced alternative traditions such as that in land use transportation modelling that build on spatial interaction in terms of transport directly, nor have these alternate approaches been disaggregated to the level at which populations are represented as relatively autonomous agents. Where disaggregation of aggregate transport has taken place, it has led to econometric models of individual choice or microsimulaton models of household activity patterns which only superficially embody the key principles of ABM. But the explosion in the availability of movement data in recent years, combined with improvements in modelling technology, is easing this process dramatically. In particular, agent-based modelling as a methodology has grown ever more promising and is now capable of emulating the interplay of urban systems and transportation. Here, we explore the importance of this approach, review how transportation has been factored into or omitted from agent-based models of urban areas, and suggest how it might be handled in future applications. Our approach is to take snapshots of different applications and use these to illustrate how transportation is handled in such models.
\end{abstract}

Keywords: Agent-based modelling; urban systems; urban modelling 


\section{Introduction}

From the time when the first cities emerged some 5000 years ago, the manner in which populations physically transported themselves was governed by prevailing technology. Taken in conjunction with the key social and economic objectives which shaped and drove the development of cities, transportation has defined the way the city interacts for the whole of their existence. Until the invention of the internal combustion engine in the late 18th century, the fastest transportation was based on horse and carriage, while the distance travelled by populations to and from work was limited to how far one could walk within an hour. Economic landscapes and city systems were thus conditioned geometrically by these distances. Moreover, within cities the polarisation of activities involving local movement to and from their market centres imposed a limit on the density of traffic: the average speed of traffic in the largest cities from ancient Rome to Elizabethan London, and even to contemporary times has never been greater than about 10 kilometres an hour on the local street systems (Morris, 1994).

Until the invention of the railways, the technologies utilised for urban transportation had barely changed over thousands of years (Schobert, 2014). The industrial revolution enabled mass transportation using the first public systems, and facilitated private means of travel such as the automobile, allowing cities to break out of the straightjacket imposed by non-automated technology. In the last 200 years, transportation has dominated cities in ways that have enabled them to grow dramatically, to sprawl across vast areas only limited by the time taken to travel and the restrictions imposed by time required at work. In the early 19th century, this meant that for the first time cities could grow well beyond their previous population limits of about 1 million persons; this nexus is changing once again as new information technologies are increasingly being used to complement and substitute for more material forms of transportation of people and goods (Batty, 2013).

Cities can only grow if the requisite transportation is in place, and problems of rapid growth depend on getting the balance between private versus public transportation right (UN-Habitat, 2010). This dynamic is particularly pronounced in the developing world, where the fastest growing cities now exist. Most cities with populations greater than 2 million persons require some form of mass transit or subway system. Much of London's explosive growth in the Victorian era necessitated the development of new technologies to support its expansion, such as the London Underground system and Bazalgette's remarkable public sanitation works, both systems which are still in active use. Cities and regions thus depend fundamentally in terms of their spatial structure on flows between activities and the populations that create and operate them, which are profoundly shaped by the physical networks that connect them together. For over 200 years, economists have argued that space itself is a critical factor in determining how industries locate and how cities function. Markets bring demand and supply together through a clearing mechanism which provides a functioning system in which prices and rents determine how land is allocated in the production and consumption of economic and social activities. Distance and its usual 
formalisation as an inferior good - which in general suggests that on balance, we want less of it rather then more of it - is the basic arbiter of how cities are structured. Transportation is central to this and is enshrined in the basic notion best articulated by Tobler (1970) in his famous first law of geography: "... everything is related to everything else, but near things are more related than distant things". Transport is intrinsic to this principle or law and it appears directly or indirectly in most models of urban systems.

Not all models incorporate transportation. However, in particular those developed using systems dynamics (see Forrester, 1969) - and thus appropriate conceptions of distance and transport - are key to the way urban models must operate (Batty, 1971). Brockmann and Helbing (2013) make this point simply and elegantly, showing that the seemingly chaotic spread of disease can be easily modelled as a simple function of what they term "effective distance". Thus, as transportation networks structure and dictate an emergent cost of movement, it is important to bring them to bear when we attempt to study processes that rely on distance and interaction.

Modelling cities is a Herculean task, and historically researchers who might have wished to include transportation in their models faced a variety of challenges to incorporating transport data. Access to data has always been an obvious limitation, as has been the way we embody networks into such models. Even as tools and data have become more accessible, theoretical conundrums remain with respect to how we determine where to draw the line of abstraction in attempting to understand transportation. For example, accessibility has changed with the advent of new technologies, and researchers must choose whether to include socioeconomic factors such as car ownership or bus usage in their model. Some researchers have tried to get around the problem of transport by drawing upon Simon's (1996) concept of the near-decomposability of systems, in which parts of a system interact among themselves in clusters or subgraphs, with interactions among subsystems being relatively weaker or fewer but not negligible. This is what Forrester (1969) articulated in his Urban Dynamics model, in which transport became insignificant due to the fine spatial granularity of the model. Essentially he abstracted the problem into one of interacting regions so that the model might focus on activities solely with one such region. In fact, many agentbased models focus on urban problems without really addressing the question of transportation, omitting it as a factor in processes such as gentrification, regeneration, urban sprawl, crime, agricultural land use, land markets, and disease models as we will highlight in this chapter.

In the remainder of this chapter, we first identify how transport enters a wide array of models of urban systems, pointing to agent-based models as having quite rudimentary conceptions of transportation embedded within them. Section 2 will give an overview of how land use transportation interaction (LUTI) models, disaggregate economic choice models (sometimes called discrete choice), and microsimulation models all incorporate transport directly, and give an overview of agent-based modelling with its contrasting approach. This variety of approaches to transportation within the existing literature sets the context for a discus- 
sion of the current state of the field. In Section 3, we lay out a framework for understanding the complexity of the transportation models utilised by existing agent-based models, which we utilise as a guide in application domains in Sections 3.1-3.4. The chapter concludes with Section 4, a summary and outlook for the field of agent-based modelling and transportation.

\section{Simulation Models for Urban Transportation}

The first computer models of urban systems were based on transportation and emerged in the early to mid-1950s in parallel with the development of mainframe computers for transactions processing in government and business. The development of the digital computer was closely linked to scientific applications in which transport was an early focus, as were location-allocation, input-output modelling, and commodity and trade flow analysis. The first operational models were built in 1955 for policy analysis for the Chicago Area Transportation Study (Boyce and Williams, 2015). These models were essentially aggregative simulations of flows of traffic between what came to be called origins and destinations, invariably defined by dividing the city into small zones. The models in question originated from analogies between classical Newtonian physics and human flows using ideas about gravitation and potential. In this, the inverse square law was central; thus from the very beginning of the discipline, distance became the key organising factor of transportation modelling.

These models became the basis for the standard four stage transport model which is still today the workhorse of transportation planning (Ortuzar and Willumsen, 2011). Models were built to generate trips within small zones (the first stage); gravity models were then used to distribute flows between origin and destination zones according to distance and the attraction of these zones (the second stage); the flows were then split into different modes using econometric type statistical models (modal split, the third stage); the resultant flows were assigned to the network (the fourth stage) so that congestion could be evaluated and the network changed if necessary. These models are highly aggregate in that they simulate total flows on different modes of transit networks and their segments, usually at peak hour. They are only implicitly dynamic, as they simulate only a total number of trips taken at the peak hour: in this sense, they are equilibrium models (Batty, 2008). As they were developed, they came to be disaggregated in terms of trip types and trip maker categories and a new theory based on how typical travellers - or agents - made choices between different locations emerged. These discrete choice models are consistent with more aggregate gravity-spatial interaction styles of models; their populations as agents do not communicate with one another. However, such models do attempt to represent the system at the level of the behavioural unit (Ben-Akiva and Lerman, 1985), albeit with respect to generic probability distributions applicable to any individual trip maker.

The development of discrete choice modelling in the 1970s gave way to microsimulation models of traffic. These essentially model the decisions of the 
household or trip-makers in households with respect to their daily activity patterns, representing the city in complete detail with all agents being represented (or in the case of really massive systems, with a sample percentage, usually 10 percent, of the individuals represented (Horni et al., 2016). In these models, the agents again do not communicate, influencing one another indirectly through the congestion they generate for one another with its resulting cost to the household activity budget. The best example of these kinds of models is MATSIM which was developed from the US initiative in the TRANSIMs model in the early 1990s (Horni, Nagel, and Axhausen, 2016). More recent work (Padgham et al., 2014) has explored the integration of a Belief-Desire-Intention decision making component within MATSIM, allowing the model to incorporate more nuanced behaviours and interactions.

Aggregate, disaggregate, and household activity microsimulation transport models quickly spawned extensions to land use modelling, which in turn have generated their own tradition by fusing ideas about density, rents, housing markets, economic base and input-output analysis with locational decision-making. These have come to be called LUTI models and, in general, operate by separating out transport from land use but taking standard four stage transport models and linking these through a loose coupling to their land use equivalents. Some such as UrbanSim have attempted to specify populations at the individual, agent-based level (Waddell, 2002); these are often referred to as agent-based equivalents of urban models (Batty, 2012). They again do not incorporate communication, thus making coordination or purposive (joint) action impossible to model.

Historically, then, there have been many different kinds of transport models, many of which are relatively top-down, aggregate, or non-interactive. More modern approaches such as microsimulation or agent-based modelling have sought to rectify the dynamics which elude older models. Agent-based modelling (ABM) is a simulation methodology which breaks a system down into individual actors, or agents, which interact with one another and with their environment based on their own individual attributes and behavioural rules (Epstein and Axtell, 1996; Miller and Page, 2007; Cederman, 2002). They are distinct from microsimulation models, in which large random samples of a population of individuals are progressively advanced through statistical transitions based on their individual attributes (see Crooks and Heppenstall, 2012). The line between microsimulation and $\mathrm{ABM}$ is indeed very blurred, as there exist microsimulation models which incorporate minimal social networks to guide their decision-making (e.g. the demand for eldercare as modelled in Gilbert and Troitzsch, 2005) and ABMs in which interaction occurs exclusively through environmental variables (e.g. the most basic, baseline implementation of the SugarScape model of Epstein and Axtell, 1996). On the other hand, the two approaches are moving towards a more common ground as microsimulation models add more behavioural and spatial interaction between individual units and ABM add both space and demographic characteristics to their agents (Birkin and $\mathrm{Wu}, 2012$ ). In this work, we proceed with the definition of $\mathrm{ABM}$ that requires explicit interaction among agents for 
a model to be considered an ABM. In the interests of length, we will leave microsimulation and household activity models of transport such as MATSIMs to one side (see Horni et al., 2016 for more information), focusing exclusively on how transportation is represented in agent-driven models that do not attempt to model the transportation system or the transportation planning process per se.

In light of this individual focus, it is important to address a factor of individuallyoriented models which is frequently elided, namely the unit of behavioural representation. Agent-based models that directly address the transportation system are usually conceived in terms of the movement of persons and the way they interact with one another; this tends to exclude vehicles which often remove the personal, interactive element of $\mathrm{ABM}$ in favour of fixed route systems which promote mixing. Accordingly, most ABMs for transport have tended to abstract from the transportation system per se, and in the following work, we will demonstrate several of these kinds of models relating to crime, segregation, and disease within cities. An exception to this general trend is in pedestrian modelling, where the agents are mainly pedestrians (although other elements of the built environment may be treated as fixed or mobile agents; e.g. Torrens, 2014). In such models, agents come into physical contact and also generate crowding, flocking, and herding effects that emerge from their interactions. Sometimes these sorts of models are coupled to decision-making sequences that pertain to the social and economic context, such as movement to purchase goods in shopping centres; there can be quite complex linkages between agents, goods, and the transport of these to other locations that feature in such models (Heppenstall et al, 2012).

All of these dynamics can be more powerfully addressed thanks to the growing supply of data. With increasing availability of the kind of fine-grained data that allows for high-quality agent-based models to be applied to systems, ABM can be applied to a growing range of locations and contexts. In particular, as we will see, ABM tends to be much more detailed with respect to particular sectors of the urban system where there is much more emphasis on detailed behavioural mechanisms that are composed of a variety of rules that define the ways in which such models function. ABM offers us a new lens through which we can focus on human populations as individuals and groups in models - and through which we can critically simulate their physical and social movements in ways that were never possible before. Given the promise of this new technology, in the following sections, we explore the relationship between transportation and ABM, presenting broad categories of models to better explore how the same processes have been addressed by different researchers.

One final point is worth making before we review transportation in ABM, and it involves networks. As transport models largely abstract from the transport network in terms of the way models of transport flow are articulated and only load these flows back onto networks for operational purposes, the network has never been the subject of any exhaustive analysis in transportation modelling. Not so in ABM, where the network itself in terms of its structure is often central to the way agents interact. In ABM, trends of feedback and emergence which 
are reflected in network processes can be key drivers of higher-level patterns. In this sense, we would argue that ABM is much more closely linked to network science and its developments than traditional transportation modelling that has never focussed on the morphology of the network per se.

\section{Tiers of Complexity in Agent-based Modelling}

Our review here will present examples of how agent-based models have been developed for a range of urban dynamic processes which tend to focus on individual sectors of the urban system in which transportation plays a key role. In the following section, we will highlight agent-based models which successfully incorporate transportation, and especially models which utilise network properties to give more focussed understandings of transportation and distance. In fact, unlike the complete models discussed in Section 2, the models reviewed here are not built around transportation per se, as transportation is not privileged in these models over and above any other activities or features. It is important to reiterate that we will not be addressing cellular automata or other styles of models which lack either purposive agents or interactions, as these necessarily treat transportation as, at best, a fixed and invariant process. Our focus is thus on quite a narrow range of model types, namely those which deal with transportation in emergent phenomena arising from the interactions and feedbacks among agents.

Table 1. Different Tiers of Transport Complexity for ABM

\begin{tabular}{|c|l|l|}
\hline Tier & Qualities & Examples \\
\hline 0 & $\begin{array}{l}\text { Spatial environments without con- } \\
\text { straints on movement }\end{array}$ & $\begin{array}{l}\text { Agents move between home work, } \\
\text { and other location types at a con- } \\
\text { stant speed on a lattice }\end{array}$ \\
\hline 1 & $\begin{array}{l}\text { Environment constrained topologi- } \\
\text { cally, e.g. by a network or areas of } \\
\text { exclusion }\end{array}$ & $\begin{array}{l}\text { Agents move between home, work } \\
\text { etc. locations at a constant speed } \\
\text { along a road/rail/walk network }\end{array}$ \\
\hline 2 & $\begin{array}{l}\text { Topological environmental struc- } \\
\text { tures incorporating weights which } \\
\text { constrain movement }\end{array}$ & $\begin{array}{l}\text { Agents move between home, work, } \\
\text { etc. locations along a transport net- } \\
\text { work, minimising an economic cost } \\
\text { function }\end{array}$ \\
\hline 3 & $\begin{array}{l}\text { The weights of the topological } \\
\text { structure vary over the different di- } \\
\text { mensions of the simulation }\end{array}$ & $\begin{array}{l}\text { Agents move between home, work } \\
\text { etc. locations along a network with } \\
\text { fluctuating traffic levels, minimising } \\
\text { a cost function with economic and } \\
\text { temporal components }\end{array}$ \\
\hline
\end{tabular}

In order to more conveniently compare and contrast models, we will distinguish among models by defining a notional measure of the complexity, specifically orientated to transport models. Thus a model in which the entities or 
agents move freely across a continuous space or lattice includes only the most basic sense of transport; they represent space and include an implied understanding of distance, but nothing more. We call this Tier 0 complexity. Pursuing a more detailed understanding of interaction, a Tier 1 model is one in which movement is structured by a network or some other topological features. Thus for example, if a model of housing choice includes not only information that a home is near a public transit station, but is able to consider the betweenness or centrality of that station within the network, the agent's understanding of the desirability of that property is accordingly enriched. More complex still is a Tier 2 model, in which a network's edges are weighted to reflect their costs and/or benefits. Cost may be economic: a model which ignores the relative cost of a toll road fails to capture the true impact of the road on the system. Cost could also allow the agent to plan based on their personal costs due to having or lacking certain attributes: if one has access to an automobile rather than public transit alone, new parts of the network are opened and/or closed to the agent. These models may include multiple costs/benefits per edge, such as the cost in terms of time, money, unpleasantness (e.g. overfull commuter trains), pollution, and so forth. Finally, at the most complex end of the scale are Tier 3 models, which incorporate information about edges with weights that vary over different dimensions of the simulation. Driving agents can plan their day around traffic surges, for example; similarly, agents might avoid a particularly busy commuter train, stringing together a chain of public transit links to arrive at their destination in slightly more time but greater comfort. These Tier 3 models are examples of the full behavioural richness agents could emulate. At the time of writing, the authors were unaware of any agent-based model that could achieve this level of complexity. It is included here to give a sense of future research directions with respect to agent-based modelling and transportation models. The tiers are presented in Table 1 for reference. However, it should be noted that agent-based models that focus purely on transportation have been excluded from this review as the focus is on more partial subsystems of the urban system and their processes and dynamics. With this notional index of transportation complexity, we will present a number of models, identifying the origins of the model, the context to which it is applied, the entity being modelled, the spatial and temporal scales of the simulation, the modes of transit included, and some discussion of the index of transport complexity. The entities being modelled may be, for example, individuals, households, groups, or spatial areas - in short, the units within the model which are able to exhibit heterogeneous behaviours, which is one of the hallmarks of agent-based modelling. The spatial scale of the model is the size of the physical area being modelled (e.g. inside a building, neighbourhood, city, region, country, and so forth). Temporal scale is used here to mean the mapping of ticks of the simulation to units of time.

\subsection{Models of Criminal Activity}

Crime represents a high-stakes and high-profile urban issue, one for which it can be difficult to justify experiments en vivo. As such, many researchers have 
attempted to use ABM in this context. The field of crime science holds that crime is emergent from the interactions among potential offenders, potential targets, and guardians of the potential targets (Cohen and Felson, 1979), making a methodology which can simulate the behaviours of each even more attractive. It thus implies that ABM is highly applicable in that the source of the activity itself is a product of the interactions between different kinds of agents. Different models have incorporated movement and behaviour in a variety of ways as we show in Table 2.

Table 2. Typical Applications of ABM to Crime

\begin{tabular}{|c|c|c|c|c|c|c|}
\hline Author & Application & Entity & $\begin{array}{l}\text { Spatial } \\
\text { Scale }\end{array}$ & $\begin{array}{l}\text { Temporal } \\
\text { Scale } \\
\text { (units) }\end{array}$ & $\begin{array}{l}\text { Transport- } \\
\text { ation }\end{array}$ & $\begin{array}{l}\text { Transport } \\
\text { Complex- } \\
\text { ity }\end{array}$ \\
\hline \begin{tabular}{|l|}
$\begin{array}{l}\text { Dray et al. } \\
(2008)\end{array}$ \\
\end{tabular} & Crime & Individuals & City & \begin{tabular}{|l|}
$36 \quad$ months \\
(days)
\end{tabular} & Pedestrian & 0 \\
\hline $\begin{array}{l}\text { Melo et al. } \\
(2006)\end{array}$ & Crime & Individuals & City & $\begin{array}{ll}1 & \text { month } \\
\text { (minutes) }\end{array}$ & Pedestrian & 0 \\
\hline Groff (2007) & Crime & Individuals & City & \begin{tabular}{|lr}
1 & month \\
(minutes)
\end{tabular} & Road & 1 \\
\hline $\begin{array}{|ll|}\text { Wise } & \text { and } \\
\text { Cheng } & \\
(2016) & \\
\end{array}$ & Crime & Individuals & $\begin{array}{l}\text { Neighbour- } \\
\text { hood }\end{array}$ & $\begin{array}{ll}1 & \text { month } \\
\text { (minutes) }\end{array}$ & Road & 2 \\
\hline $\begin{array}{l}\text { Malleson } \\
\text { and Birkin } \\
(2012)\end{array}$ & Crime & Individuals & $\begin{array}{l}\text { Neighbour- } \\
\text { hood }\end{array}$ & $\begin{array}{|lr|}1 & \text { month } \\
\text { (minutes) }\end{array}$ & $\begin{array}{ll}\text { Road, } \\
\text { bus }\end{array}$ & 2 \\
\hline
\end{tabular}

For example, Dray et al. (2008) have developed a series of simulations that explore the impact of three different street-level policing interventions (random patrols, hot-spot policing, and problem-oriented strategies), specifically exploring how problem-oriented policing influences a drug market. Their work situates officers and civilians within an abstract lattice environment of "street blocks" representing an urban area, through which they are free to move. Similarly, Melo et al. (2016) use a grid of cells in their simulation of police patrol routes. Their work similarly treats the agents as pedestrians who move among points of interest. Groff (2007) presents a more complicated model in terms of transportation, utilising real road network data in her study of street robbery. Her work models the police randomly moving through the environment and arresting offenders as they encounter them, informed by and influenced by the real road networks of Seattle, Washington. In particular, she compares the impact of including the real road network in place of a grid or lattice, finding that the road network structure significantly impacts the outcome of the model. The introduction of even a road network enables the model to pick out simple transport dynamics.

In a similar vein, the work of Wise and Cheng (2016) includes the real road network of an area of London in the simulation of police patrolling activity. 
Car-based police officers interact with traffic lights, which vary the cost of travel depending on the timing of their arrival; officers also weight the cost of roads based on whether or not they are responding to an emergency call and may ignore traffic laws. The richness of path costs is even more clearly displayed in the work of Malleson and Birkin (2012), in which burglars move around an environment, familiarising themselves with neighbourhoods and selecting targets to burgle. Malleson and Birkin's model includes transport by road, rail, and bus, even going so far as to denote which roads are car or pedestrian accessible. This range of available transit influences the agent's familiarity with different parts of the city, a critical dynamic in the burglary target selection process. These more nuanced models are more capable of capturing the important spatial dependencies associated with crime and policing, and suggest the importance of including these factors in models.

In all these varieties of crime model, transportation is key but this is largely because crime involves intrinsic mobility with detection occurring in mobile contexts through policing and criminals invariably moving to points where crime is committed. So far there has been little thought about cybercrime and its agentbased characteristics but this like many urban activities in the digital age is an undiscovered country when it comes to simulation, as much because such crime is at first sight invisible. What is important here is that the kind of aggregate dynamics of transportation as reflected in mainstream flow modelling is simply not a feature of this style of ABM where transport is one of many features of the system being represented but by no means the sole focus of such simulations.

To an extent, many of these kinds of ABM depend upon pedestrian modelling, which is arguably the archetypal agent-based model in the social sciences. These models are frequently motivated by the sole factor of determining how pedestrians move, assuming that their purpose can be determined by their direction and their contact with other pedestrians and related fixed obstacles. Many such models are highly geometrical in that the interaction between agents and the obstacles in their environment of movement is purely physical; this is the main reason why such models have been in the vanguard of ABM. Adding behavioural factors that determine the rationale for movement is much more complicated and to date, most developments have avoided such extensions except for applications such as those noted here in crime. Good reviews of the state of the art focussing first on relations to more conventional traffic flow modelling and second in relation to more rule-driven modelling are in the papers by Bellomo and Dogbe (2011) and the thesis by Zachariadis (2015).

\subsection{Models of Disease Transmission and Diffusion}

As cities grow denser, the potential cost of epidemic disease looms larger. Historically, researchers have modelled the spread of disease using mathematical models (e.g. network propagation in Brockmann and Helbing (2013), or system dynamics (Brailsford et al., 2009). These models tend to omit dynamics such as variable individual susceptibility to disease, and struggle to incorporate space meaningfully. The particular attributes of space, distance, and interaction 
are incredibly important in understanding the spread of disease, as the variable transmission patterns of influenza versus cholera versus sexually transmitted infections (STIs) suggest. An important consideration when describing how diseases spread is the fact that space can be extremely local and relational - a patient might be infected on a bus as she travels through an area, without that area ever experiencing a reported case. The "location" of the transmission event is the bus, which is a mobile space, and any intervention would need to take that dynamic into account. To some extent some crime patterns are affected in the same way, crimes being committed in mobile situations and not registered or recorded at the point where they take place. Aleman et al. (2011) note that while contact in public spaces is an important part of the mixing that produces epidemics, ABM of disease contexts have struggled to incorporate public transit into models of urban disease epidemics.

Table 3. Typical Applications of ABM to Disease in Cities

\begin{tabular}{|l|c|l|l|l|l|l|}
\hline Author & Application & Entity & $\begin{array}{l}\text { Spatial } \\
\text { Scale }\end{array}$ & $\begin{array}{l}\text { Temporal } \\
\text { Scale } \\
\text { (units) }\end{array}$ & $\begin{array}{l}\text { Transport- } \\
\text { ation }\end{array}$ & $\begin{array}{l}\text { Transport } \\
\text { Complex- } \\
\text { ity }\end{array}$ \\
\hline $\begin{array}{l}\text { Linard et al. } \\
(2008)\end{array}$ & Disease & $\begin{array}{l}\text { Individuals } \\
\text { (Human, } \\
\text { Animal, } \\
\text { Insect) }\end{array}$ & Region & $\begin{array}{l}1 \text { Year } \\
\text { (weeks) }\end{array}$ & Pedestrian & 0 \\
\hline $\begin{array}{l}\text { Perez and } \\
\text { Dragicevic } \\
(2009)\end{array}$ & Disease & Individuals & $\begin{array}{l}\text { Neighbour- } \\
\text { hood }\end{array}$ & $\begin{array}{l}1 \text { Month } \\
\text { (hours) }\end{array}$ & Public tran- \\
sit & 1 \\
\hline $\begin{array}{l}\text { Simoes } \\
(2012)\end{array}$ & Disease & Individuals & Country & $\begin{array}{l}2 \text { Years } \\
\text { (days) }\end{array}$ & Abstract & 1 \\
\hline $\begin{array}{l}\text { Aleman et } \\
\text { al. (2011) }\end{array}$ & Disease & Individuals & City & $\begin{array}{l}1 \text { Day (min- Subway } \\
\text { utes) }\end{array}$ & 2 \\
\hline $\begin{array}{l}\text { Crooks and } \\
\text { Hailegiorgis } \\
(2014)\end{array}$ & Disease & Individuals & Region & $\begin{array}{l}\text { Months } \\
\text { (minutes) }\end{array}$ & Roads & 2 \\
\hline
\end{tabular}

The simplest models track the movement of susceptible individuals through space, as they proceed through the environment without constraint. Linard et al. (2008) present a simulation of exposure to malaria in southern France, in which humans periodically appear in locations where mosquitoes are common and animals move randomly around the environment. While there are both rural and urban areas, there are no connections among them to structure movement or the spread of disease.

Perez and Dragicevic (2009) present a more complicated model in which individuals with measles move among points of interest based on the road network. The authors associate the road network with public transit, but do not clarify how the individuals are grouped or their movements structured by the road network. In a similar vein, Simoes (2012) presents a model of individuals who 
are infected with mumps. These susceptible individuals exist within neighbourhoods through which they may move via a random graph; the neighbourhoods are connected to other neighbourhoods through their own random graph, with the urban centres themselves being connected to other urban centres throughout the country. Aleman et al (2011) have a more complicated model of the available public transit, which allows individuals to select their path based on the minimal times taken, but the dynamics of the model are not influenced by any other costs or assumptions. Thus such movement is channelled through the connected networks but otherwise unstructured.

More complex models of the agent-based interactions between disease and movement patterns do exist. Crooks and Hailegiorgis (2014) present a model in which individuals travel around an environment trying to minimise their distance travelled, while being constrained by the carrying capacity of the network edges. Thus, individual efforts to move throughout space are limited and influenced by the movements and choices of others. Further, agents make choices based on the distances between them and the desired targets of their activities, choosing where and when to move in a way that is inherently informed by distance and accessibility. Thus, agents experience a more variable set of weights which significantly impacts the amount of exposure they have on other (potentially infected) individuals, with concordant ramifications for rates of infection.

\subsection{Models of Urban Change}

As noted in the introduction to this chapter, changes in transportation technologies have allowed cities to grow at an accelerating pace. Early theorists brought broad, abstract, macro and micro models to bear on the problem, utilising mathematical structures based on micro economic considerations to understand the complex functioning of cities. Alonso (1964), for example, posited that residential location choices were a trade-off for individuals attempting to allocate fixed budgets to optimise factors such as the size of the house, their household budget for other goods, and the distance of the residence from the city centre. In this model, the distance of the house from the city centre is a de facto representation of transportation costs. The trade-off among the optimised factors in Alonso's model drives higher-level residential patterns; it represents one of the first efforts to explore how different preferences interacted to produce the patterns and structures that characterise cities. As well as forming the basis of modern urban economics, such theories set the context for various applications of agent-based models of housing markets, an early example being the NBER (National Bureau of Economic Reseach) urban simulation models developed by Ingram et al. (1972) in Harvard in the 1970s and early 1980s. More recently, agent-based models have been developed to explore processes including urban growth, land markets, gentrification, and regeneration.

Models like Alonso's effort to understand residential patterns have given rise to further research into why such growth occurs, and in particular how the role of land markets shape the development of cities. Land markets are said to exist "once land is traded as a commodity" (UN-ESCAP, 1998), and represent 
Table 4. Typical Applications of ABM to Urban Change

\begin{tabular}{|c|c|c|c|c|c|c|}
\hline Author & Application & Entity & $\begin{array}{l}\text { Spatial } \\
\text { Scale }\end{array}$ & $\begin{array}{l}\text { Temporal } \\
\text { Scale } \\
\text { (units) }\end{array}$ & $\begin{array}{l}\text { Transport- } \\
\text { ation }\end{array}$ & $\begin{array}{l}\text { Transport } \\
\text { Complex- } \\
\text { ity }\end{array}$ \\
\hline $\begin{array}{l}\text { Sasaki and } \\
\text { Box, } 2003\end{array}$ & Landuse Allocations & Farmers & Region & $\begin{array}{l}\text { Decades } \\
\text { (years) }\end{array}$ & Abstract & 0 \\
\hline $\begin{array}{l}\text { Crooks, } \\
2007\end{array}$ & Land Rents & \begin{tabular}{|l|} 
Households, \\
Businesses
\end{tabular} & Region & $\begin{array}{l}\begin{array}{l}\text { Decades } \\
\text { (years) }\end{array} \\
\end{array}$ & Abstract & 0 \\
\hline $\begin{array}{|ll|}\text { Filatova } & \text { et } \\
\text { al., } 2009 & \end{array}$ & Land Markets & \begin{tabular}{|l} 
Buyers, \\
Sellers
\end{tabular} & Region & $\begin{array}{l}\text { Abstract } \\
\text { (ticks) }\end{array}$ & Abstract & 0 \\
\hline $\begin{array}{l}\text { Magliocca } \\
\text { et al., } 2011\end{array}$ & Land Markets & \begin{tabular}{|l} 
Consumer, \\
Developer, \\
Farmer
\end{tabular} & Region & $\begin{array}{l}\text { Abstract } \\
\text { (ticks) }\end{array}$ & Abstract & 0 \\
\hline $\begin{array}{ll}\text { Gilbert } & \text { et } \\
\text { al., } 2009 & \end{array}$ & Housing Markets & \begin{tabular}{|l|} 
Buys, \\
Sellers, Es- \\
tateAgents, \\
Property
\end{tabular} & $\begin{array}{l}\text { Neighbour- } \\
\text { hood }\end{array}$ & $\begin{array}{l}\text { Abstract } \\
\text { (ticks) }\end{array}$ & Abstract & 0 \\
\hline \begin{tabular}{|l} 
Diappi \\
Bolchi,
\end{tabular} & Gentrification & $\begin{array}{l}\text { Owner, } \\
\text { Landlord, } \\
\text { Tenant, } \\
\text { Developer, } \\
\text { Property }\end{array}$ & $\begin{array}{l}\text { Neighbour- } \\
\text { hood }\end{array}$ & $\begin{array}{l}\text { Decades } \\
\text { (years) }\end{array}$ & Abstract & 0 \\
\hline $\begin{array}{l}\text { Liu and } \\
\text { O'Sullivan, } \\
2016\end{array}$ & Gentrification & Household & Region & \begin{tabular}{|l} 
Decades \\
(years)
\end{tabular} & Abstract & 0 \\
\hline $\begin{array}{l}\text { Torrens, } \\
2006\end{array}$ & Urban Growth & \begin{tabular}{|l|} 
Households, \\
Employers, \\
Developers, \\
Planners
\end{tabular} & Region & $\begin{array}{l}\text { Decades } \\
\text { (years) }\end{array}$ & Roads & 1 \\
\hline \begin{tabular}{|lrl} 
Xie et & al., \\
2007 & & \\
\end{tabular} & Urban growth & Households & Region & $\begin{array}{l}\text { Decades } \\
\text { (years) }\end{array}$ & Roads & 1 \\
\hline $\begin{array}{|lr|}\text { Jackson } & \text { et } \\
\text { al., 2008 } & \\
\end{array}$ & Gentrification & Renters & $\begin{array}{l}\text { Neighbour- } \\
\text { hood }\end{array}$ & $\begin{array}{ll}2 & \text { Years } \\
\text { (months) }\end{array}$ & Roads & 2 \\
\hline $\begin{array}{l}\text { Torrens and } \\
\text { Nara, } 2007\end{array}$ & Urban Regeneration & $\begin{array}{l}\text { Property, } \\
\text { Resident, } \\
\text { Market }\end{array}$ & $\begin{array}{l}\text { Neighbour- } \\
\text { hood }\end{array}$ & $\begin{array}{l}\text { Decades } \\
\text { (years) }\end{array}$ & Roads & 2 \\
\hline $\begin{array}{|ll|}\text { Jordan } & \text { et } \\
\text { al., } 2014 & \\
\end{array}$ & Residential Mobility & $\begin{array}{l}\text { Households, } \\
\text { Houses }\end{array}$ & $\begin{array}{l}\text { Neighbour- } \\
\text { hood }\end{array}$ & \begin{tabular}{|l} 
Decades \\
(years)
\end{tabular} & Roads & 2 \\
\hline \begin{tabular}{|l|} 
Haase et al., \\
2010
\end{tabular} & Land Markets & Households & City & \begin{tabular}{|l}
$\begin{array}{l}\text { Decades } \\
\text { (years) }\end{array}$ \\
\end{tabular} & Roads & 2 \\
\hline
\end{tabular}

an important driver and shaper of urban form. The pricing of that commodity, obviously, is partially driven by features such as the accessibility of a piece of land via various forms of transit. A particularly interesting aspect of land markets is that, unlike labour or capital markets, land is immobile and finite. Currently less than five percent of the earth's surface is urban; with urban populations predicted to grow to 5 billion by 2030, the urban footprint will still account 
for less than 10 percent of the surface (Seto et al., 2011). Understanding land markets is important as such markets heavily influence where people can live, and how they will change their cities in the near future.

At a finer spatial scale, another important aspect of cities is the process of how neighbourhoods change over time. Areas are developed due to many factors, accessibility being one of the most important as areas change and decline. For example, affluent households sometimes move to suburbs for the better opportunities offered by modern housing (e.g. Burgess, 1927); this leads to higher rates of rental tenancy in vacated houses. In another trend, landlords of inner city properties might under-maintain their properties, which leads to rapid depreciation in some neighbourhoods. If an area has declined, it has the possibility of being gentrified under certain conditions, gentrification being defined as "the transformation of a working-class or vacant area of the central city into middleclass residential and/or commercial use (Lees et al., 2008). While gentrification has a relatively long history, it was not until Smith's (1979) Rent Gap Hypothesis appeared that aspects of gentrification could be explored in a model. The theory attempts to show that certain areas are gentrified based on the dynamics of residential property values and location - in particular, how accessible the area is to other parts of the city, as abstracted by distance from the urban centre (an abstraction inspired by the work of Burgess (1927) and Hoyt (1939)). Thus, in the dynamics of urban change at a range of spatial and temporal scales, accessibility, distance, and transport all shape the space within which people make decisions about housing and land purchases. We show a collection of agent-based models which demonstrate these dynamics and processes in Table 4.

Some of these models are derived from classic theories and are relatively nave in their inclusion of the impact of transport on urban systems. Many of the residential location models have been developed which are in essence simple agentisations of classic theories, such as von Thünen's location theory of residential development by Sasaki and Box (2003) or Alonso's (1964) land rent theory by Crooks (2007). In such models, the agentisation process allows for dynamic behaviours to be added to static theories, but the representation of distance or transportation cost is understandably simplistic. The work of Filatova et al. (2009) and Magliocca et al. (2011) deal with the buying, development and selling of land, while Gilbert et al., (2009) represent specific properties: all represent space as a continuous area without associated variable costs (i.e. distance from the transport network). As with models of classic land market theories, simulations which implement traditional models of gentrification (e.g. Diappi and Bolchi, 2008; Liu and O'Sullivan, 2016) have tended to include only a Cartesian sense of distance into the model. They represent Tier 0 complexity, in that they acknowledge that physical space impacts the functioning of the system but ignore variable costs of any kind.

Torrens (2006) and Xie et al. (2007) are two examples of urban change models which include slightly more developed representations of transport. In both models, the agents themselves are rather abstract. For example, the Torrens (2006) model simulated urban sprawl around Lake Michigan, abstracting the 
various agents that impact growth - such as Households, Employers, Developers, Planners - into a category called "agents of change". Similarly, the model of Xie et al. (2007) explored the change from rural to urban land-use in the Wuxian City region of China, with agents representing developers and townships (collections of households). In both models, transportation is only considered with respect to the development potential of the land. For example, in Torrens (2006), the presence of nearby existing roads made the development of land more likely.

Xie et al. (2007) modelled transportation infrastructure more explicitly, incorporating the distance from the potential site of development to the economic activity of the town centres into the likelihood of area development. Such abstraction of agent types and the use of transportation is understandable in that such models are extensions of the more widely used Cellular Automata modelling style often used to explore land use change and urban growth (e.g. Clarke et al., 1997). The key difference between these models and CA is that the emphasis is more on the decision making process of the agents, rather than a probability of a cell transitioning from one land use to another. These models of change take place over the course of years, and include notions of distance or transportation in only a topologically constrained fashion, making them arguably Tier 1 in terms of transport complexity.

More spatially informed models of urban change also exist. For example, Jackson et al. (2008) model a potentially gentrifying neighbourhood in part of Boston, representing variable location costs to the agents based on the agent's characteristics and their impact on the area's relative accessibility. Torrens and Nara's (2007) work in Salt Lake City, Utah, similarly assesses the qualities of different locations based on accessibility to a bundle of different resources, taking the work further by considering the interaction between the household's socioeconomic status and that bundle of accessibilities. Jordan et al. (2014) similarly weight the attractiveness of different housing options based on whether the household in question had a car and, accordingly, what their relative transportation options would be. Other models like Haase et al., (2010) study economic decline, again factoring in variable distances and travel costs based on household type. These examples can be said to achieve Tier 2 complexity, as the cost of the distance is more or less important based on the attributes of the households. These represent some of the most advanced examples of transport complexity in ABM currently being simulated.

\section{Discussion: The Growing Importance of Transportation in $\mathrm{ABM}$}

The work presented here is a brief snapshot of a variety of ways researchers have chosen to think about and study urban system dynamics as they are influenced by transportation in the context of agent-based modelling and how this relates to the broader field of transportation modelling. Different researchers have adopted different assumptions about how space, closeness, and accessibility shape the environment in which agents operate. It is important, then, to understand how the 
social, physical, informational, and market dynamics which drive these processes are assumed to be influenced by transport distance rather than naive distance. These assumptions have been shown to have impacts for the dynamics of these models: different fidelities of physicality and mobility implied by transport result in different patterns of movement and behaviour, and therefore in a sense represent different models altogether (e.g. Groff, 2007). Thus, researchers need to be explicit in their assumptions, precise in their descriptions of transit and movement, and open with their implementations of movement and transport.

It is important to note that one of the tiers of transportation complexity introduced in Section 3, that of Tier 3, could not be found in the reviewed literature. This finer-grained understanding of transit has yet to be achieved in agent-based models, and we suggest that future researchers consider designing their simulations with these specifications in mind. One potential way of overcoming this is the merging of microsimulation and agent-based modelling techniques, an emerging research agenda given form by Birkin and Wu (2012). An example of this move toward unity is reflected in the recent work of Horni et al. (2016), which exemplifies the way that the MATSim framework is seeking to blend techniques to better capture traffic dynamics as a function of demographic and physical qualities within a study area. The achievability of incorporating more and more complex models of road, pedestrian, public transit, rail, air, and informal transport within agent-based models of processes influenced by transport will only grow with increasing data accessibility. Even simple models will be increasingly powerful in this era of new and fine-grained data. Specifications such as the General Transit Feed Specification (GTFS) will allow researchers to capture an ever-growing range of information about public transit, and the flowering of sensor technology will provide new information about cars and pedestrians. Turning this data into meaningful information and comparing it with simulated data will push the boundaries of the technologies even further, and help us to understand the true nature of the processes at work. The interplay between simulation and observation has the potential to identify new dynamics, discard disproven correlations, and measure the interaction among them. The synthesis of these new forms of modelling and data represents a major challenge as well as an incredible opportunity to explore the true processes at work in these complex systems, which have thus far eluded us.

Incorporating a more focussed presentation of distance and closeness requires that agent-based models must become both more complicated and more complex. The linking together of diverse models and processes is a major current theme in agent-based modelling, and the broader field of modelling more generally (see, for example, Jha et al., 2004; Wang et al., 2016, for applications of models which bridge technologies). This speaks to a larger concern about how generalisable models are, and whether it is advisable or, practically speaking, possible to combine them. These points of complicatedness and complexity must be considered separately.

In terms of being complicated - that is, ungainly to implement and test there are steps that researchers can and arguably should be taking to ensure 
that models can be integrated with one another. Focusing more on building frameworks rather than one-off constructions or proofs of concept can allow for reasonably well-validated transport systems to be incorporated into models in general which seek to study more expansive, transport-informed systems. Indeed, abstracting transportation out of the model design process could actually have the effect of simplifying many models and facilitating the docking of the different models as the pieces of the simulation become more modular. This is something that has already been achieved in alternative transport models built by engineers and planners and what is now needed is some form of synthesis that combines the best of each (Boyce and Williams, 2015). Their 'complicatedness' is a problem which can be dealt with by abiding by responsible best practices with simulation design.

The complexity of these models is arguably a greater concern. In discussing complexity here, we mean the way in which the components of the model combine to create higher-level effects which are absent from the individual components. This is, obviously, the core and indeed purpose of ABM, but it raises questions of model parsimony. The simulator cannot model the world in all of its complexity, and must at some point accept some level of abstraction as a cut-off. With the increasing availability of nuanced data tracking transport information across wide regions at the granularity of seconds, there exists the temptation to create slavishly detailed simulations of transport. Researchers must consider what tier of transport complexity is really required for each of the processes they are incorporating into the model, and ensure that the model constructed is the cleanest and simplest model possible (but no simpler). Ideally, integration between different types of models will allow researchers to optimise on the strengths of different methodologies. Whether this is best accomplished through an explicitly integrated series of standards or simply by stringing together the output of one model into another in a loose coupling remains to be seen. The assumptions researchers make, however, must be clear and the treatment of space and transport well-considered, lest the double-edged sword of complexity threaten the interpretability of the results.

Transportation models that have been built primarily for simulating predicted future traffic flows and land use locations do provide a sense of how transport is considered as a completely integrated system within cities. But most of the models have been extremely aggregative, and in this sense are not able to address detailed policy-making objectives (e.g. socio-economically informed access to transit). Moreover, as they have always attempted to simulate the most aggregative of activities, they fail to address detail that is often needed when individual subsystems or sectors of the city system become the subjects of analysis and policy (e.g. regeneration schemes). Even where these models have been disaggregated to the household level, the straightjacket in which householder behaviour with respect to travel is considered narrows the scope that is possible in testing new kinds of scenario and focuses still on traffic flows, capacity, and congestion. There are however, several features of more aggregate transport models that can be incorporated in ABM. In particular summaries of transportation 
flows and levels of mobility are incorporated in a variety of indices of accessibility as we outlined in the previous section. Accessibility measures combine various indicators of geometry, distance, travel costs and locational benefits in such a way that they are consistent with underlying transportation flow modelling. Moreover, combined with much more detail about transportation networks, ABM do have some real possibilities for simulating transport at a much finer behavioural and spatial resolution than anything hitherto. The current stumbling block is that most agent-based models that incorporate transportation do so in ways that are not easily scalable to more comprehensive systems where many sectors such as crime, health, policing and so on are considered in an integrated way.

From this brief review, it is clear that agent-based show promise with respect to modelling aspects of urban systems but explicit transportation is often lacking and that some synthesis is required with respect to integration. Already transport per se is being rapidly broadened to embrace concerns about mobility in general, but in ABM some of the physicality of existing transport models needs to be modelled explicitly, to reflect the fact that transport at the end of the day involves physical movements and infrastructures. Of course the idea that much of transport in the future will be ethereal - by email, social media and so on does not make this notion any less real but simply expands the transport herein to embrace the virtual as well as physical. Agent-based models will be central to expanding these horizons so that policy can truly begin to reflect some of the challenges raised by transportation issues in the future city.

\section{References}

1. Aleman D M, Wibisono T G, and Schwartz B, 2011. A nonhomogeneous agent-based simulation approach to modeling the spread of disease in a pandemic outbreak, Interfaces, 41(3): 301-315.

2. Alonso W, 1964. Location and land use: toward a general theory of land rent, Harvard University Press, Cambridge, MA.

3. Batty M, 1971. Modelling cities as dynamic systems, Nature, 231: 425-428.

4. Batty M, 2008. Fifty years of urban modelling: macro-statics to micro-dynamics, in Albeverio S, Andrey D, Giordano P, and Vancheri A (eds.), The Dynamics of Complex Urban Systems: An Interdisciplinary Approach, Springer Physica-Verlag, New York, NY, pp. 1-20.

5. Batty M, 2012. A generic framework for computational spatial modelling, in Heppenstall A J, Crooks A T, See L M, and Batty M. (eds.), Agent-based Models of Geographical Systems, Springer, New York, NY.

6. Batty M, 2013. The new science of cities, MIT Press, Cambridge, MA.

7. Bellomo N and Dogbe C, 2011. On the modeling of traffic and crowds: a survey of models, speculations, and perspectives, SIAM Review, 53(3): 409-463.

8. Ben-Akiva M and Lerman S. R, 1985. Discrete choice analysis: theory and application to travel demand, MIT Press, Cambridge, MA.

9. Birkin M, and $\mathrm{Wu} \mathrm{B}$ M, 2012. A review of microsimulation and hybrid agent-based approaches, in Heppenstall A J, Crooks A T, See L M, and Batty M (eds.), Agentbased Models of Geographical Systems, Springer, New York, NY.

10. Boyce D E, and Williams H C W L, 2015. Forecasting urban travel: past, present and future, Edward Elgar Publishing, Cheltenham, UK, 
11. Brailsford S C, Berchi R, De Angelis V, and Mecoli M, 2009. System dynamics models to assess the risk of mosquito-borne diseases and to evaluate control policies, Discussion Papers in Centre for Operational Research, Management Science and Information Systems, University of Southampton, Southampton, UK.

12. Brockmann D and Helbing D, 2013. The hidden geometry of complex, networkdriven contagion phenomena, Science, 342(6164): 1337-1342.

13. Burgess E W, 1927. The determinants of gradients in the growth of a city, Publications of the American Sociological Society, 21: 178-84.

14. Cederman L E, 2002. Endogenizing geopolitical boundaries with agent-based modeling, Proceedings of the National Academy of Sciences of the United States of America, 99(Suppl 3): 7296-7303.

15. Clarke K C, Hoppen S, and Gaydos L J, 1997. A self-modifying cellular automaton model of historical urbanization in the San Francisco Bay area, Environment and Planning B, 24(2): 247-261.

16. Cohen L E and Felson M, 1979. Social change and crime rate trends: a routine activity approach, American Sociological Review, 44(4): 588-608.

17. Crooks A T, 2007. Experimenting with cities: utilizing agent-based models and gis to explore urban dynamics, PhD Thesis, University College London, London, England.

18. Crooks A T and Hailegiorgis A B, 2014. An agent-based modeling approach applied to the spread of cholera, Environmental Modelling and Software, 62: 164-177.

19. Crooks A T and Heppenstall A J, 2012. Introduction to agent-based modelling, in Heppenstall A J, Crooks A T, See L M, and Batty M. (eds.), Agent-based Models of Geographical Systems, Springer, New York, NY.

20. Diappi L and Bolchi P, 2008. Smith's rent gap theory and local real estate dynamics: a multi-agent model, Computers, Environment and Urban Systems, 32(1): 6-18.

21. Dray A, Mazerolle L, Perez P, and Ritter A, 2008. Policing Australia's "heroin drought": using an agent-based model to simulate alternative outcomes, Journal of Experimental Criminology, 4(3): 267-287.

22. Epstein J and Axtell R, 1996. Growing artificial societies: social science from the bottom up, Brookings Institution, MIT Press, Cambridge, MA.

23. Filatova T, Parker D, and van der Veen A, 2009. Agent-based urban land markets: agent's pricing behavior, land prices and urban land use change, Journal of Artificial Societies and Social Simulation, 12(1). Available at http://jasss.soc.surrey.ac.uk/12/1/3.html.

24. Forrester J W, 1969. Urban dynamics, MIT Press, Cambridge, MA.

25. Gilbert N, Hawksworth J C, and Swinney P A, 2009. An agent-based model of the English housing market, Association for the Advancement of Artificial Intelligence. Available at http://www.aaai.org/Papers/Symposia/Spring/2009/SS-09-09/SS0909-007.pdf.

26. Gilbert N and Troitzsch K, 2005. Simulation for the social scientist, Milton Keynes, UK: Open University Press.

27. Groff E R, 2007. Situating simulation to model human spatio-temporal interactions: an example using crime events, Transactions in GIS, 11(4): 507-530.

28. Haase D, Lautenbach S, and Seppelt R, 2010. Modeling and simulating residential mobility in a shrinking city using an agent-based approach, Environmental Modelling and Software, 25(10): 1225-1240.

29. Heppenstall A J, Crooks A T, See L M, and Batty M. (eds.) 2012. Agent-based models of geographical systems, Springer, New York, NY. 
30. Horni A, Nagel K, and Axhausen K W (eds.) 2016. The multi-agent transport simulation MATSim, Ubiquity, London.

31. Hoyt H, 1939. The structure and growth of residential neighbourhoods in American cities, Federal Housing Administration, Washington, DC.

32. Ingram G K, Kain J F, and Ginn R, 1972. The Detroit prototype of the NBER urban simulation model, NBER, New York, NY.

33. Jackson J, Forest B, and Sengupta R, 2008. Agent-based simulation of urban residential dynamics and land rent change in a gentrifying area of Boston, Transactions in GIS, 12(4): 475-491.

34. Jha M, Moore K, and Pashaie B, 2004. Emergency evacuation planning with microscopic traffic simulation, Transportation Research Record, 1886(1): 40-48.

35. Jordan R, Birkin M, and Evans A, 2014. An agent-based model of residential mobility assessing the impacts of urban regeneration policy in the EASEL district, Computers, Environment and Urban Systems, 48: 49-63.

36. Lees L, Slater T, and Wyly E, 2008. Gentrification, Routledge, New York, NY.

37. Linard C, Poncon N, Fontenille D, and Lambin E F, 2008. A multi-agent simulation to assess the risk of malaria re-emergence in southern France, Ecological Modelling, 220(2): 160-174.

38. Liu C and O'Sullivan D, 2016. An abstract model of gentrification as a spatially contagious succession process, Computers, Environment and Urban Systems, 59: $1-10$.

39. Magliocca N, Safirova E, McConnell V, and Walls M, 2011. An economic agentbased model of coupled housing and land markets (CHALMS), Computers, Environment and Urban Systems, 35(3): 183-191.

40. Malleson N and Birkin M, 2012. Analysis of crime patterns through the integration of an agent-based model and a population microsimulation, Computers, Environment and Urban Systems, 36(6): 551-561.

41. Melo A, Belchior M, and Furtado V, 2006. Analyzing police patrol routes by simulating the physical reorganization of agents, in Sichman J S and Antunes L (eds.), Multi-Agent-Based Simulation VI, Springer, Berlin, Germany.

42. Miller J and Page S, 2007. Complex adaptive systems: an introduction to computational models of social life, Princeton University Press, Princeton, NJ.

43. Morris A E J, 1994. History of urban form: before the industrial revolutions (3rd ed.), Longman, London.

44. Ortúzar J de Dios and Willumsen L G, 2011. Modelling transport (4th ed.), John Wiley, New York, NY.

45. Padgham, L, Nagel, K, Singh, D, and Chen, Q, 2014) Integrating BDI agents into a MATSim simulation, Frontiers in Artificial Intelligence and Applications, DOI: 10.3233/978-1-61499-419-0-681.

46. Perez L and Dragicevic S, 2009. An agent-based approach for modeling dynamics of contagious disease spread, International Journal of Health Geographics, 8: 50.

47. Sasaki Y and Box P, 2003. Agent-based verification of von Thünen's location theory, Journal of Artificial Societies and Social Simulation, 6(2). Available at http://jasss.soc.surrey.ac.uk/6/2/9.html.

48. Schobert H H, 2014. Energy and society: an introduction (2nd ed.), CRC Press, Boca Raton, FL.

49. Seto K C, Fragkias M, Güneralp B, and Reilly M K, 2011. A meta-analysis of global urban land expansion, PloS One, 6(8): e23777.

50. Simoes J, 2012. An agent-based/network approach to spatial epidemics, in Heppenstall A J, Crooks A T, See L M, and Batty M. (eds.), Agent-based Models of Geographical Systems, Springer, New York, NY. 
51. Simon H A, 1996. The sciences of the artificial (3rd ed.), MIT Press, Cambridge, MA.

52. Smith N, 1979. Toward a theory of gentrification: a back to the city movement by capital not people, Journal of the American Planning Association, 45(4): 538-548.

53. Tobler W, 1970. A computer movie simulating urban growth in the Detroit region, Economic Geography, 46(2): 234-240.

54. Torrens P M, 2006. Simulating sprawl, Annals of the Association of American Geographers, 96(2): 248-275.

55. Torrens P M, 2014. High-fidelity behaviors for model people on model streetscapes, Annals of GIS, 20(3): 139-157.

56. Torrens P M and Nara A, 2007. Modelling gentrification dynamics: a hybrid approach, Computers, Environment and Urban Systems, 31(3): 337-361.

57. UN-ESCAP, 1998. Urban land policies for the uninitiated, United Nations Economic and Social Commission for Asia and the Pacific, New York, NY. Available at http://www.unescap.org/huset/land_policies/index.htm.

58. UN-Habitat, 2010. State of the cities 2010-11 - cities for all: bridging the urban divide, UN-Habitat, Nairobi, Kenya. Available at http://www.unhabitat.org/content.asp?cid=8891\&catid=643\&typeid=46\& subMenuId $=0 \&$ AllContent $=1$.

59. Waddell P, 2002. UrbanSim: modeling urban development for land use, transportation, and environmental planning, Journal of the American Planning Association, 68(3): 297-314.

60. Wang H, Mostafizi A, Cramer L A, Cox D, and Park H, 2016. An agent-based model of a multimodal near-field tsunami evacuation: decision-making and life safety, Transportation Research Part C: Emerging Technologies, 64: 86-100.

61. Wise S and Cheng T, 2016. How officers create guardianship: an agent-based model of policing, Transactions in GIS, DOI: 10.1111/tgis.12173.

62. Xie Y, Batty M, and Zhao K, 2007. Simulating emergent urban form: desakota in China, Annals of the Association of American Geographers, 97(3): 477-495.

63. Zachariadis V, 2014. Modelling pedestrian systems, Doctoral Thesis, UCL (University College London), London. Available at http://discovery.ucl.ac.uk/1435418/. 